\title{
Notes on Numeration:
}

\section{Arithmetic on a Checkerboard Numerals for the Blind}

\author{
Phillip S. Jones \\ Mathematics Department \\ University of Michigan \\ Ann Arbor, Michigan 48109
}

\section{The Local Arithmetic of John Napier and Walter Minto}

In 1617 John Napier published a little book Rabdologiae, Seu Numerationis Per Virgulas Libri Duo in which he described his "bones" or "rods." These are often used as an illustrative or enrichment device in teaching about numeration today ${ }^{(1)}$. These became so popular that historians largely lost sight of the other computational devices which were included in the back of Napier's book.

These additional devices and their connection with the binary system came to my attention as I studied the work of Walter Minto. Minto (1753-1796) had emigrated from Scotland to become Professor of Mathematics (1787-1796) at the College of New Jersey, now Princeton University. Before coming to the United States he had collaborated with David Stewart, Earl of Buchan in producing An Account of the Life, Writings, and Inventions of John Napier of Merchiston. This book, which was cited by Thomas Jefferson in some of his mathematical writings ${ }^{(2)}$, included an extended discussion, almost the complete translation, of the Rabdologiae.

The section which describes the use of the checkerboard was titled "Local Arithmetic". Here "local" refers to what we would call a placevalue system, and is, in fact, an implicit use of the binary system which has not been adequately recognized by historians ${ }^{(3)}$. Minto's version begins, "Local arithmetic is the art of calculating by means of counters on a chess board or similar table. Divisions at the right and bottom are labeled with the geometric progression, 1, 2, 4, 8, 16, 32, etc., which are called local numbers. Common numbers (vulgari numeri) are reduced to local by subtraction, and local numbers to common by addition. Numbers are represented by putting counters on the squares corresponding to the local numbers. The common number 1875 , for example, expressed in local numbers will be found to be $1024 ; 512 ; 256 ; 64 ; 16 ; 2$; and 1 : and vice versa",(4).

The cut-away drawing of Figure 1 shows how 1875 was recorded by putting counters in the proper squares of the right hand column of a ruled board. A counter was placed opposite 1024 since it is the largest power of 2 less than 1875 . The difference between 1875 and 1024 is 851 . A counter was next placed opposite 512 since it is the largest power of 2 less than 851 , etc. The second and third columns from the right in Figure 


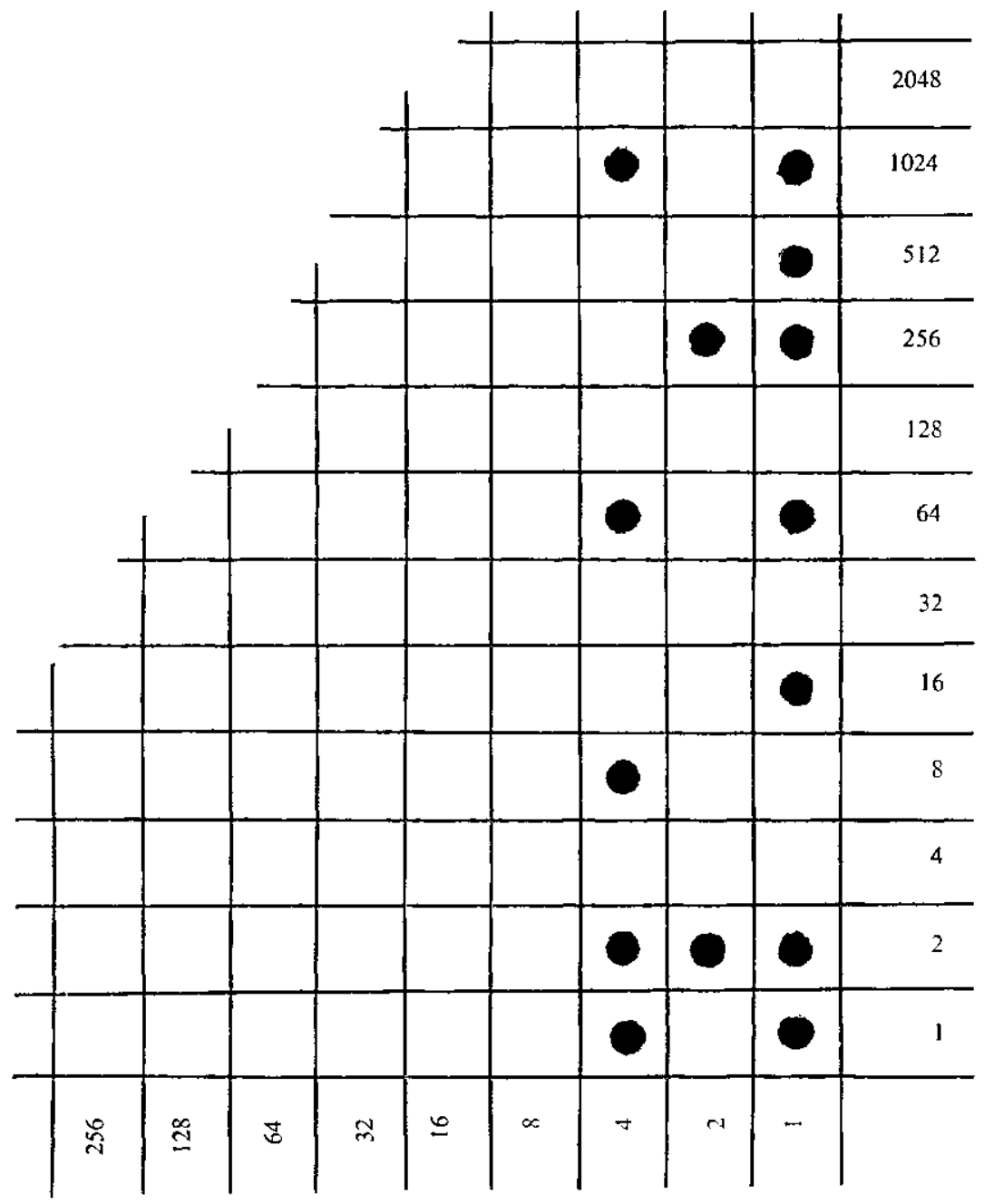

Figure 1,

1 represent $258=256+2$ and $1099=1024+64+8+2+1$. The sum of these three numbers was found by moving the counters horizontally into the right hand column, but while doing this, wherever two counters occurred at the same level, taking them off the board and replacing them by one counter at the next higher level. The final local number was then translated back into a common number by addition. In modern notation this would be represented as 


$$
\begin{aligned}
1875 & =11101010011_{2} \\
258 & =100000010_{2} \\
1099 & =10001001011_{2} \\
\hline 3232 & =110010100000_{2}
\end{aligned}
$$

Today this process would seem to offer little or no simplification in addition or subtraction.

\section{Multiplication on a Checkerboard}

Napier's scheme showed a somewhat greater saving and a reduction in the prerequisite knowledge when it was applied to multiplication. Our Figure 2 is "Fig. VIII" of the Buchan-Minto book and corresponds to the figure on page 138 of Rabdologiae. It shows a board set up to find the product, $19 \times 13$. The first number is represented by counters placed along the bottom margin and the second by counters along the right hand margin. All the squares which are opposite a pair of these original counters have also been covered with counters. The multiplication process be-

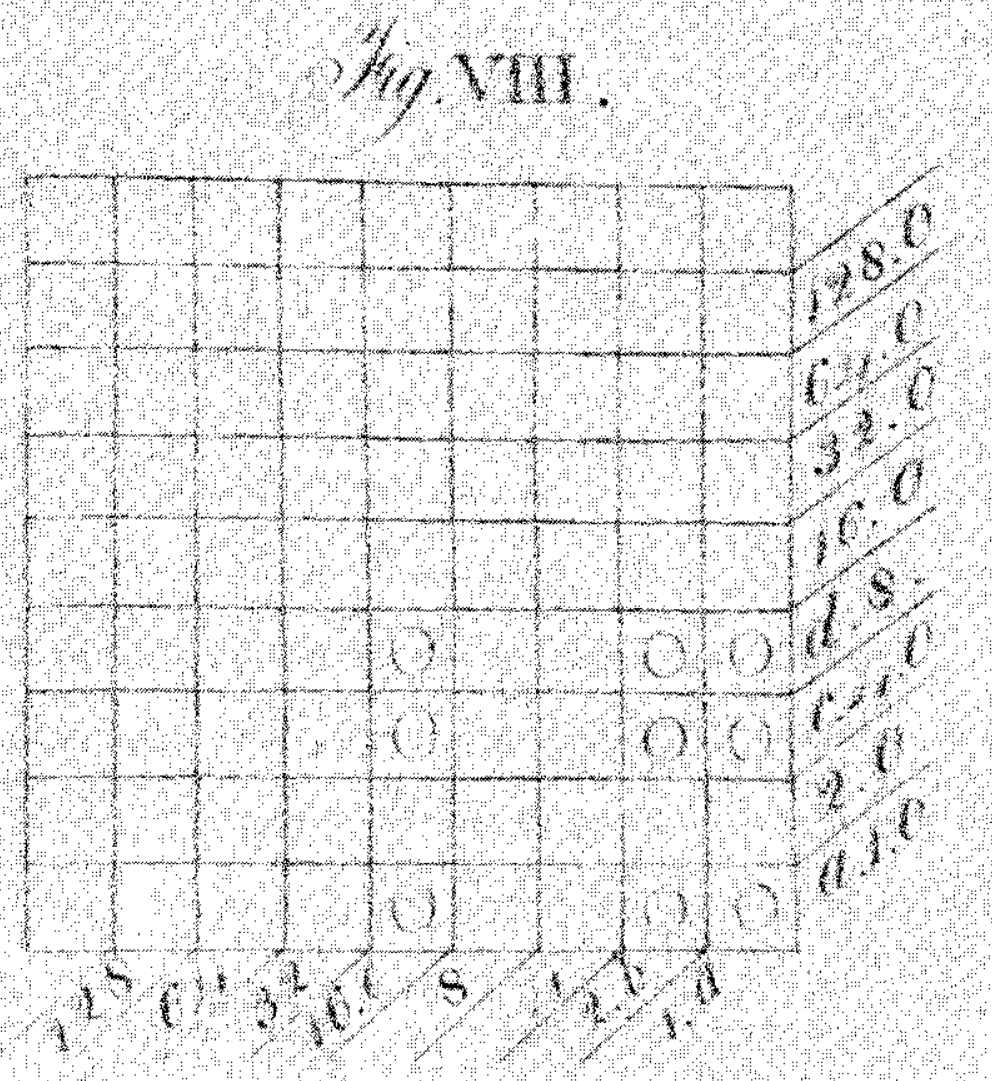

FIGURE 2. 
gins by moving the counter in the upper left position of the array. In this example this is the position 16-8 corresponding to 16 on the lower and 8 on the right hand margin. This counter is moved diagonally upward and to the right until it comes to rest in the right hand column at 128. The same move is applied to all other pieces on the board. When two pieces or counters come to rest on the same square in the right hand column, they are removed and a single counter placed in the next higher position. Thus, when the piece in the 16-1 position is moved, it picks up the piece in the 2-8 position and as a result one counter is placed in the 1-32 position on the right rather than two counters in the $1-16$ position. In modern notation this move says that $2^{\dot{4}} \times 2^{0}=2^{4}, 2^{1} \times 2^{3}=2^{4}$, and $2^{4}+2^{4}=$ $2^{5}$. These operations on the chessboard mechanically set up all the partial products, add the exponents of the powers of two by the diagonal movement which rises one level for each unit of horizontal movement, and sum the partial products. Both Napier and Buchan-Minto stress the analogy with chess by pointing out that the movements allowed the counters are those of the knight and the bishop-or, in the older terminology of Napier, of the elephant and the archer.

The algorithms for subtraction, division, and square root with local numbers are of less importance and interest. They are fairly easily reconstructed as the inverses of the processes we have outlined. We omit any discussion of them. However, a few historical remarks may add interest and pedagogical utility.

The use of a ruled board or cloth with counters was not new even in Napier's day. Few of them have survived until today, but a fourteenth century drawing in Barnard's The Casting Counter and the Counting Board $^{(5)}$ looks very much like Napier's diagram. However, the methods for recording sums and computational procedures on it were entirely different. Squared or checkered counting boards and cloths were less common than the non-squared reckoning-board or loose counter abacus. It is interesting to note that the squared type of reckoning-board was the origin of our modern word exchequer. The Oxford English Dictionary lists, "The King's Exchequer. Under the Norman and Angevin kings of England: An office or department of State managed by the Treasurer, the Justiciary, and-. Its function combined the collection and administration of the royal revenues with the judicial determination of all causes relating to revenue .... The name originally referred to the table covered with a cloth divided into squares on which the accounts of the revenue were kept by counters." The first recorded use of the word "exchekers" in English is dated $1292^{(6)}$.

The second major ingredient of Napier's local arithmetic was the use of the geometric progression $1,2,4,8, \ldots$ Progressions and the related proportions and means played a role in Pythagorean Arithmetica, and examples of geometric progressions are to be found in earlier Egyptian 
and Babylonian mathematics. However, Napier's idea that every integer can be represented as the sum of terms of a geometric progression with common ratio 2 and the association of these terms with a sequence of positions in an ordered array can be viewed today as an adumbration of a base two, place-value system. His use of the term local numbers further emphasized this connection, and yet there is no indication in the Rabdologiae that Napier had the idea of a generalized base-place value numeration system. It is true that he recognized the importance of Simon Stevin's 1585 invention of decimal fractions. Note that the positions in Figure 2 are labeled $1.0,2.0,4.0$, etc. rather than merely $1,2,4$, etc. In fact Napier's discussion of this notation in connection with logarithms and Kepler's use of it in his work with logarithms were important factors in speeding the adoption of decimal notation.

\section{Position Notation Without (?) a Zero}

Napier elaborated one device which could, at first glance, appear to show that a zero is unnecessary in a position value numeration system. Note that in our Figure 2 the positions where there are markers are also labeled with letters. That is in the right hand column 1.0, 4.0, and 8.0 are also labeled a, c, d. By associating the letters of the alphabet, in order, with the powers of 2 Napier showed how to use the concepts of his local arithmetic without the board or counters. This was discussed in separate chapters in his section on local arithmetic in the Rabdologiae, but omitted in the Buchan-Minto summary. In "Caput V" Napier says "to add $a$ $c d e h$ to $b c f g h$, you first write them together, $a b c c d e f g h h$ and then "reduce" by abbreviation". Reduction is accomplished by replacing any pair of letters by the letter which follows it in the alphabet. Thus the $c c$ in the sum would be replaced by $d$. However, upon doing this there are now two d's. They are replaced by an $e$. The resulting two $e$ 's are replaced by an $f$, etc. until the final sum is $a b h i$ which represents 1 $+2+128+256$. The total problem in modern binary notation would be

$$
\begin{array}{r}
10011101_{2} \\
+\quad 11100110_{2} \\
\hline 110000011_{2}
\end{array}
$$

This literal numeration makes five symbols, $a c d e h$ do the work of eight, 10011101, and appears to omit the zero as well as to lead to quite a neat algorithm for addition. Actually, of course the use of a zero in the numeration is implicit in the 1-1 mapping from the ordered alphabet to the powers of two. A missing letter in the alphabetic numeral corresponds to a zero in the modern binary notation. Here the absence of a mark is a symbol.

When the final score of Napier's achievements is reckoned, it does not seem to be quite fair to give him credit for having, knowing, or originat- 
ing, binary notation. He was on the brink of "putting it all together" (an important, even crucial gestalt or element of mathematical invention, as well as a modern colloquialism), but he didn't quite make it. His other accomplishments, however, will suffice to preserve a place for him in the history of mathematics.

\section{Saunderson's Palpable Arithmetic}

Occasional references to blind persons who did mathematics are found as early as the first century B.C. ${ }^{(7)}$, but the first blind mathematician of substance and importance was the Englishman Nicholas Saunderson (1682-1739). His mathematical achievements do not approximate those of the most famous blind mathematician, Leonard Euler (1707-1783). However, Saunderson was remarkable for the fact that he did master and teach advanced mathematics in spite of having lost not only his sight but his eyes as a result of smallpox and infection at the age of twelve months. Euler first lost the sight of one eye in 1725 and did not become totally blind until after the age of sixty.

Saunderson's major mathematical contribution was his book, The Elements of Algebra published posthumously in 1740. This book contains a biography of Saunderson compiled by a group of friends, as well as "Dr. Saunderson's Palpable Arithmetic Decypher'd"' by John Colson, who was Saunderson's successor as Lucasion Professor of Mathematics at Cambridge University.

Saunderson's palpable arithmetic was a system for representing numbers using pins inserted into holes in a board. This board was a little more than a foot square. The holes were spaced about a tenth of an inch apart so that the board resembled a rectangular grid with one hundred intersections per square inch. Each of the digits 0 through 9 was represented by one or two pins positioned in a square defined by three rows of three holes each. The center hole of each square was marked by a largeheaded pin except when the square was to represent 1 . In this latter case the center of the square was marked with a small- headed pin. If the square was to represent 0 , it was marked by the large-headed central pin only. All digits other than 0 and 1 were denoted by a square with two pins, the large-headed central pin and a small-headed pin in one of the eight outer holes surrounding the center position.

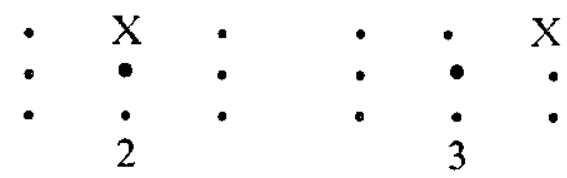

FiguRE 3

In Figure 3 we have represented 2 and 3 showing a heavy central circle to represent the large-headed pins. The " $x$ " marks show the positions for 
the small-headed pins. A small-headed pin in the top center represented 2. The digits for 3 through 9 were represented successively by placing the small-headed pin in the outer holes in clockwise order.

Figure 4 is taken from Colson's article. Its left hand "Fig. I" shows the representations of the successive digits. Its "Figure II" shows palpable arithmetic representations of 94084 and a series of five digit numerals. This system is much like modern Braille writing which, however, uses patterns of raised dots based on an arrangement of three rows of two positions each.

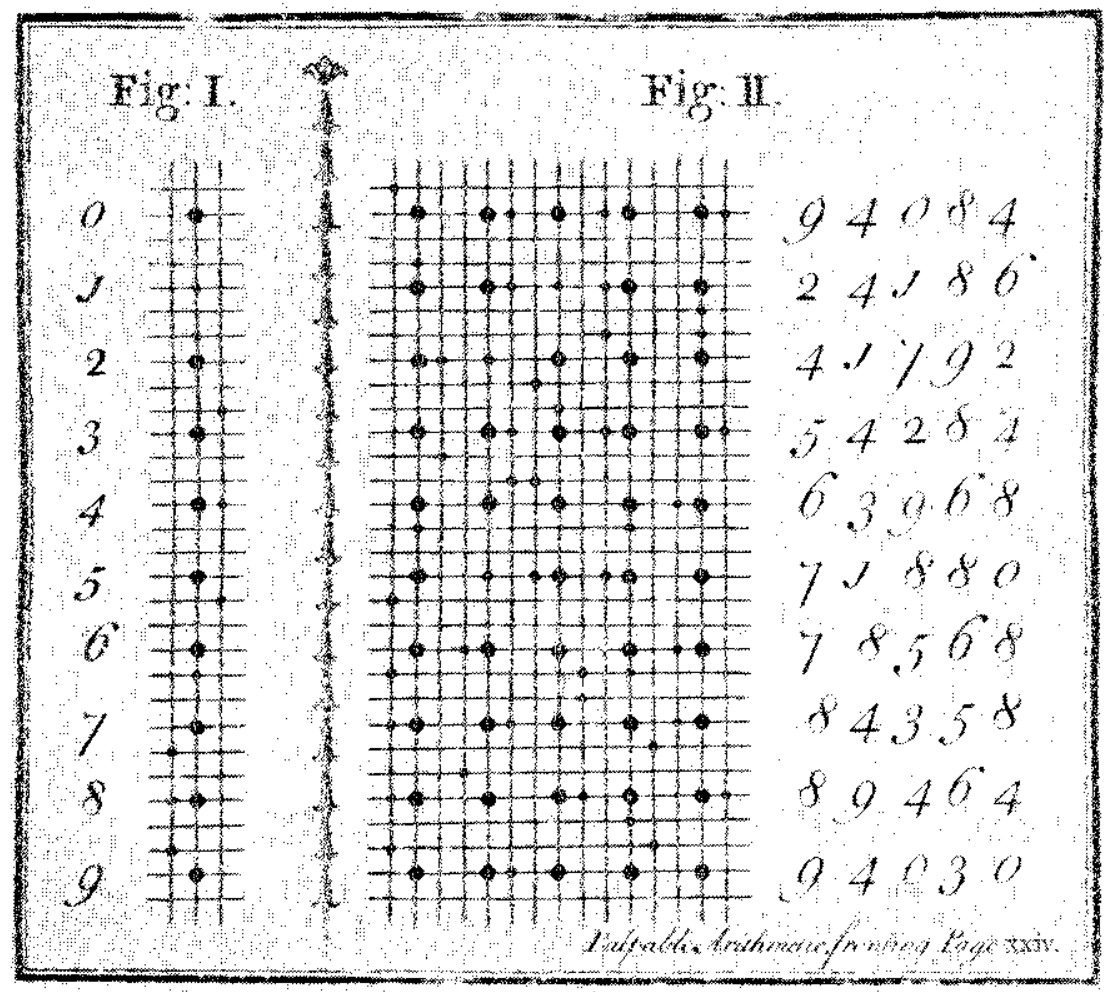

Figure 4 .

Saunderson was said not only to carry on extensive calculations using his palpable arithmetic board but also to have used it to describe geometric figures. He did this much as one might do it with a modern geoboara, using pins set in rows or pins with strings tied around them to represent geometric figures.

Saunderson, in seeking to overcome his own visual handicap, developed both devices and a concern for clarity of expression and explanation which made him a good teacher, who spent long hours teaching and working with students. He never learned to write but he dictated "manu- 
scripts" for his two volume algebra and a book on "fluxions", Newtonian style calculus, both of which were published after his death. The algebra was quite influential, going through several editions and being translated into French and German. The Lords Justices of England granted his wife, son, and daughter what would today be called a copyright on it to honor him and help them. It is to be regretted that he never told how he did his computations. All we know of his "palpable arithmetic" is this scheme for representing numerals.

\section{NOTES}

1. See Phill.1P S. JONEs, "Tangible Arithmetic. I. Napier's and Genaille's Rods", The Mathematics Teacher. vol. 47 (Nov. 1954) pp. 482-7 and the follow-up note in vol. 48 (April 1955) p. 250; Martin Gardner, "Mathematical Games", The Scientific American vol. 228 (March 1973), pp. 110-113. A facsimile edition of Rabdologiae was published by Otto Zeller in Osnabrück in 1966.

2. David Eugene Smith and Jekuthiel. Ginsburg, A History of Mathematics in America Before 1900. Chicago: The Mathematical Association of America (1934), p. 61.

3. ANTON GLASER, History of Binary and Other Nondecimal Numeration. Southampton, Pennsylvania: 1971, does not mention Napier. Martin Gardner loc. cit., mentions but does not explain Napier's two secondary computing devices.

4. BUCHAN-MINTO, op cit. p. 34.

5. Francis Pierrepont Barnard, The Casting-Counter and the Counting-Board. Oxford: The Clarendon Press, 1916. Plate XLIV. See also pp. 230, 237.

6. The Compact Edition of the Oxford English Dictionary. Oxford University Press, 1971. vol. 1 p. 917.

7. The biographers of Saunderson cite a reference to a Diodotus Stoicus in the Tusculanae Disputationes of Cicero (Marcus Tullius Ciccro, 106-43 B.C.) and mention Didymus of Alexandria Eusebius and Nicasius de Voerda of Mechlin on page ix of "Memoirs of the Life and Character of Dr. Nicholas Saunderson" which they prefixed to his Algebra.

\section{WOMEN TURNING TO ENGINEERING}

"I don't want to be a woman engineer," says Jean Luning, "just an engineer who happens to be a woman." The 19-year-old Maryland sophomore's attitude toward what was, until recently, an almost exclusively male occupation is shared by many of her classmates at Duke University's School of Engineering.

Women are flocking into engineering schools across the nation, drawn by starting salaries of more than $\$ 1,200$ a month-the highest for any women's professional group-and the challenge of the work, according to Dr. Marion Shepard.

Shepard is associate dean of the Duke engineering school, and he's seen the number of women there jump sharply in the last five years. In 1972, he said in an interview, only seven freshmen women walked through the doors; by 1977, there were 49.

"Women now constitute 22 per cent of the students here," Shepard said. "There are 159 women and 566 men, one of the highest ratios in the nation."

Women aren't the only student minority to seek engineering career, the Duke official said. Blacks are enrolling at the school at the national average of 7 per cent of the student body. 